\title{
THE ORGANIZATIONAL AND TACTICAL ASPECTS OF INITIATING A CRIMINAL CASE AND CONDUCTING A PRELIMINARY INVESTIGATION AT THE INITIAL STAGE ON THE FACTS OF CAUSING PROPERTY DAMAGE BY DECEPTION OR ABUSE OF TRUST COMMITTED IN THE FIELD OF GENERATION, TRANSMISSION AND SALE OF ELECTRIC POWER
}

\author{
Svyatoslav Yu. Biryukov \\ Vladimir M. Shynkaruk \\ Volgograd State University, Volgograd, Russian Federation
}

Volgograd Academy of the Ministry of Internal Affairs of the Russian Federation, Volgograd, Russian Federation

\begin{abstract}
Mikhail A. Shmatov
Volgograd Academy of the Ministry of Internal Affairs of the Russian Federation, Volgograd, Russian Federation
\end{abstract}

Introduction: in the modern world, energy is the basis for the development of basic industries that determine the progress of social production. In all industrialized countries, the pace of energy development was faster than that of other industries. A specific feature of electricity as a commodity is that its generation, transmission, distribution and consumption occur simultaneously; it cannot be stored and (or) preserved. It is impossible to imagine life without electric energy. The electric power industry has penetrated into all spheres of human activity: industry and agriculture, science and space, and our everyday life. In many ways, it is precisely because of the demand for $\Sigma$ electricity for the structure of the criminal situation in modern Russia that the crimes committed in the electricity sector have become characteristic; according to the statistics, the number of facts of unaccounted electricity consumption is growing by $11 \%$ annually, which leads to an increase in accounts receivable for electricity from bona fide consumers. The electric power industry is characterized by such characteristic features as the presence of long, complex distribution networks, imperfect designs of metering devices, the availability of power supply lines in the areas of consumer connection and the impossibility of their large-scale periodic monitoring by the staff of the power supply organizations. All this creates the preconditions for committing crimes in this sphere. However, for the goals of criminal proceedings to be achieved, the authorized law enforcement officials must correctly and in strict accordance with the criminal procedure law organize and carry out their activities at the stage of initiating a criminal case. The analysis of the current investigative and judicial practice shows that the bodies of preliminary investigation and inquiry make, both as at this stage and at the stage of preliminary investigation, a large number of errors that affect the legality and validity of the decisions on initiating a criminal case and all subsequent decisions in the criminal case. In this regard, the authors set a goal to reveal the organizational and tactical aspects of initiating a criminal case and conducting an investigation at the initial stage on the facts of causing property damage by deception or abuse of trust committed in the field of generation, transmission and sale of electricity. Methods: the (a) methodological framework for this study is a set of methods of scientific knowledge, among which the main ones 
are the methods of information processing and logical analysis, synthesis, induction, deduction and generalization. Results: the authors' meaning of organizational and tactical features of initiating a criminal case and conducting a preliminary investigation at the initial stage on the facts of causing property damage by deception or abuse of trust committed in the sphere of production, transmission and sale of electricity, based on the judicial and investigative practice, makes it possible to use them in the practical activities of the authorized law enforcement officials during the detection and investigation of the above-mentioned crimes. Conclusions: the study identified the organizational and tactical features of initiating a criminal case and conducting a preliminary investigation at the initial stage on the facts of causing property damage by deception or abuse of trust committed in the field of generation, transmission and sale of electricity in order to inform law students, the teaching staff of law schools, as well as the practitioners in order to better understand the features of investigating crimes of this category.

Key words: energy, electricity, procedural audit, initiation of criminal case, abuse of confidence.

Citation. Biryukov S.Yu., Shynkaruk V.M., Shmatov M.A. The Organizational and Tactical Aspects of Initiating a Criminal Case and Conducting a Preliminary Investigation at the Initial Stage on the Facts of Causing Property Damage by Deception or Abuse of Trust Committed in the Field of Generation, Transmission and Sale of Electric Power. Legal Concept, 2020, vol. 19, no. 1, pp. 112-119. (in Russian). DOI: https://doi.org/10.15688/lc.jvolsu.2020.1.16

\title{
ОРГАНИЗАЦИОННО-ТАКТИЧЕСКИЕ АСПЕКТЫ ВОЗБУЖДЕНИЯ УГОЛОВНОГО ДЕЛА И ПРОИЗВОДСТВА ПРЕДВАРИТЕЛЬНОГО РАССЛЕДОВАНИЯ НА ПЕРВОНАЧАЛЬНОМ ЭТАПЕ ПО ФАКТАМ ПРИЧИНЕНИЯ ИМУЩЕСТВЕННОГО УЩЕРБА ПУТЕМ ОБМАНА ИЛИ ЗЛОУПОТРЕБЛЕНИЯ ДОВЕРИЕМ, СОВЕРШЕННЫХ В СФЕРЕ ПРОИЗВОДСТВА, ПЕРЕДАЧИ И СБЫТА ЭЛЕКТРОЭНЕРГИИ
}

\author{
Святослав Юрьевич Бирюков \\ Волгоградская академия МВД России, г. Волгоград, Российская Федерация \\ Владимир Маркович Шинкарук \\ Волгоградский государственный университет, г. Волгоград, Российская Федерация \\ Михаил Андреевич Шматов \\ Волгоградская академия МВД России, г. Волгоград, Российская Федерация
}

\begin{abstract}
Введение: в современном мире энергетика является основой развития базовых отраслей промышленности, определяющих прогресс общественного производства. Во всех промышленно развитых странах темпы развития энергетики опережали темпы развития других отраслей. Специфической особенностью электроэнергии как товара является то, что ее производство, передача, распределение и потребление происходят одновременно, ее невозможно складировать и (или) хранить. Представить себе жизнь без электрической энергии уже невозможно. Электроэнергетика вторглась во все сферы деятельности человека: промышленность и сельское хозяйство, науку и космос, наш быт. Востребованность электроэнергии явилась определяющим фактором того, что преступления, совершаемые в сфере электроэнергетики, стали характерны для структуры криминогенной обстановки современной России; по данным статистики количество фактов неучтенного потребления электроэнергии растет на 11 \% ежегодно, что влечет за собой увеличение дебиторской задолженности за электроэнергию со стороны добросовестных потребителей. Электроэнергетика имеет такие характерные особенности, как наличие протяженных сложных по конфигурации распределительных сетей, несовершенство конструкций приборов учета, доступность линий электроснабжения на участках абонентских вводов и невозможность их масштабного периодического контроля со стороны персонала энергоснабжающих организаций. Все это создает предпосылки для совершения преступлений в данной сфере.
\end{abstract}


Однако для того, чтобы цели уголовного судопроизводства были достигнуты, уполномоченные должностные лица правоохранительных органов должны правильно и в точном соответствии с уголовно-процессуальным законом организовать и осуществить свою деятельность на стадии возбуждения уголовного дела. Анализ современной судебно-следственной практики показывает, что органы предварительного расследования и дознания допускают как на данной стадии, так и на стадии предварительного расследования большое количество ошибок, которые сказываются на законности и обоснованности принятых решений как о возбуждении уголовного дела, так и на принятие всех последующих решений по уголовному делу. В связи с этим авторами поставлена цель раскрыть организационно-тактические аспекты возбуждения уголовного дела и осуществления расследования на первоначальном этапе по фактам причинения имущественного ущерба путем обмана или злоупотребления доверием, совершенных в сфере производства, передачи и сбыта электроэнергии. Методы: методологическую основу данного исследования составляют совокупность методов научного познания, среди которых основное место занимают методы обработки информации и логического анализа, синтеза, индукции, дедукции и обобщения. Результаты: представленное в работе авторское содержание организационно-тактических особенностей возбуждения уголовного дела и производства предварительного расследования на первоначальном этапе по фактам причинения имущественного ущерба путем обмана или злоупотребления доверием, совершенных в сфере производства, передачи и сбыта электроэнергии, опирающееся на судебно-следственную практику дает возможность использовать их в практической деятельности уполномоченных должностных лиц правоохранительных органов в ходе выявления и расследования вышеназванных преступлений. Выводы: в результате исследования определены организационно-тактические особенности возбуждения уголовного дела и производства предварительного расследования на первоначальном этапе по фактам причинения имущественного ущерба путем обмана или злоупотребления доверием, совершенных в сфере производства, передачи и сбыта электроэнергии, в целях информирования обучающихся по направлению подготовки «Юриспруденция», педагогических работников юридических вузов, а также практических работников для более полного понимания особенностей расследования преступлений указанной категории.

Ключевые слова: энергетика, электроэнергия, процессуальная проверка, возбуждение уголовного дела, злоупотребление доверием.

Цитирование. Бирюков С. Ю., Шинкарук В. М., Шматов М. А. Организационно-тактические аспекты возбуждения уголовного дела и производства предварительного расследования на первоначальном этапе по фактам причинения имущественного ущерба путем обмана или злоупотребления доверием, совершенных в сфере производства, передачи и сбыта электроэнергии // Legal Concept = Правовая парадигма. - 2020. - Т. 19, № 1. -C. 112-119. -DOI: https://doi.org/10.15688/lc.jvolsu.2020.1.16

\section{Введение}

Возбуждение уголовного дела - стадия уголовного процесса, представляющая собой фундамент всего судопроизводства: своевременность и грамотность действий уполномоченных лиц компетентных органов на этой стадии опосредует оперативность и эффективность решения всего комплекса задач, стоящих перед уголовно-процессуальным законом.

В соответствии с действующим уголовно-процессуальным кодексом России следователь (дознаватель) в любом случае выявления признаков общественно опасного деяния обязан принять исчерпывающие меры, направленные на установление события деяния, установление и изобличение лиц, причастных к его совершению. Поступающие в правоохранительные органы сообщения о гото- вящихся, либо совершенных преступлениях подлежат обязательной проверке.

Уполномоченные должностные лица правоохранительных органов, перечень которых дан в уголовно-процессуальном кодексе России, в пределах установленной уголовно-процессуальным законом компетенции при наличии определенного в законе повода и при достаточности оснований принимают решение о возбуждении уголовного дела, оформляя данное решение соответствующим постановлением. В любом случае для принятия законного и обоснованного решения о возбуждении уголовного дела необходимы два взаимосвязанных элемента: повод и основание.

Главная задача процессуальной проверки - определение наличия или отсутствия в имевшем место деянии признаков какого-либо состава преступления [1, с. 116; 3, с. 159; 5]. 


\section{Организационно-тактические аспекты возбуждения уголовного дела}

По уголовным делам о преступлениях по фактам причинения имущественного ущерба путем обмана или злоупотребления доверием, совершенных в сфере производства, передачи и сбыта электроэнергии, типичными поводами выступают заявления физических и юридических лиц, пострадавших от преступления, либо рапорт об обнаружении признаков преступления, который готовится на основании результатов оперативно-розыскных мероприятий $[6$, с. $122 ; 7$, с. 34]. Основанием же по вышеизложенным фактам выступают данные, указывающие на наличие необходимых признаков данного преступления, которые зачастую относятся к объективной стороне и объекту преступления.

Для установления достаточных оснований к возбуждению уголовного дела по фактам причинения имущественного ущерба путем обмана или злоупотребления доверием, совершенных в сфере производства, передачи и сбыта электроэнергии, необходимо провести следующие процессуальные и организационные действия:

- получить объяснение от заявителя (таковым может выступить как физическое лицо, так и ресурсоснабжающая организация, которой причинен материальный вред; в таком случае объяснение получается от представителя данной организации). В объяснении должны найти свое отражение следующие данные: когда, каким образом стало известно о факте совершения преступления - причинения материального вреда; где, когда, в какой период времени, каким образом он причинен и в каком размере; какие документы отражают данный факт; какими действиями был причинен материальный вред (несанкционированное подключение, использование специальных технических средств и пр.); кто еще может располагать значимой для расследования информацией. Причем при получении объяснений и проведении последующих допросов лицо, производящее расследование, обязано к ним должным образом подготовиться, в том числе изучить значение специальных терминов, используемых в данной сфере хозяйствования, с тем, чтобы правильно понимать показания лиц, а также дать возможность представить себя в достаточной степени компетентным в данной отрасли [1, с. $116 ; 4$, с. 40$]$;

- произвести осмотр места происшествия. По преступлениям указанной категории в качестве места происшествия может быть осмотрено несколько объектов: место несанкционированного подключения, применения специальных технических средств и пр., где основными задачами осмотра будет являться установление обстоятельств совершения действий, образующих объективную сторону преступления, поиск, фиксация и изъятия следов преступления (в узком смысле слова); помещения управляющей компании, где задачами осмотра будет являться обнаружение и изъятие гражданско-правовых и бухгалтерских документов, содержащих в себе информацию, касающуюся расследуемого события. Такими документами будут являться:

- учредительные документы управляющей компании;

- лицензии или разрешения на определенные виды деятельности и др.;

- приказы о назначении на должность (приеме на работу) руководителей, иных должностных лиц и работников, подозреваемых в совершении преступления, заключенные с ними трудовые договора, должностные инструкции; - договора на продажу коммунальных ресурсов (электрической энергии), бухгалтерские документы: документы, отражающие совершение соответствующих операций, в том числе: расчет потребности электроэнергии для конкретных объектов, потребление в месяц, потребление в год; документы, подтверждающие финансовые операции между ресурсоснабжающей организацией, управляющей компанией, потребителями, в том числе: счета-фактуры за услуги в конкретные периоды времени, оборотно-сальдовые ведомости, движение денежных средств по кассе, начисление работникам заработной платы, приходные кассовые ордера, платежные ведомости, платежные поручения; документы, подтверждающие факты отключения электроэнергии; акты сверки взаимных расчетов по состоянию на конкретный период времени; акты ревизий и камеральных проверок;

- гражданско-правовые договоры с управляющими компаниями, акты сверок на начало и конец конкретных временных периодов; 
сведения по претензионной работе с подрядчиками и третьими лицами;

- документы, подтверждающие факт поставки электроэнергии конкретным физическим лицам или организациям и др.

Перечисленные документы (их копии) могут быть также получены по запросу лица, производящего расследование, или изъяты на основании ст. 21 УПК РФ.

Истребовать в соответствующем Информационном расчетном центре сведения:

- о начисленных и собранных средствах в счет оплаты услуг ресурсоснабжающим организациям с разбивкой по видам поставляемых ресурсов;

- сальдовую ведомость по ресурсоснабжающим организациям на начало и конец рассматриваемого периода;

- акты сверок с управляющими компаниями и ресурсоснабжающими организациями на начало и конец рассматриваемого периода.

Указанные документы необходимо изучить с участием специалиста-бухгалтера (ревизора) с целью установления признаков необоснованности либо неправильности начисления, списания или перечисления денежных средств, товарно-материальных ценностей, установления тарифов и др. В случае выявления указанных признаков затребовать в обслуживающих кредитных организациях сведения о движении денежных средств по расчетным счетам управляющих компаний, изъять соответствующие документы у юридических лиц - контрагентов управляющих компаний, а затем назначить и провести необходимые документальные исследования полученных сведений (либо назначить экономические судебные экспертизы) с целью установления причин возникновения задолженности, а также определения динамики задолженности управляющих компаний; выяснить время возникновения наибольшей части задолженности.

\section{Организационно-тактические аспекты производства предварительного расследования на первоначальном этапе}

В случае установления лиц, возможно причастных к совершению преступлений, получить у них образцы почерка и подписи, после чего провести необходимые почерковедческие и, если это необходимо, техникокриминалистические исследования первичной бухгалтерской и гражданско-правовой документации.

Отдельного внимания заслуживает направление поручений органу дознания в целях установления лиц, причастных к совершению данного преступления; лиц, которые могут обладать криминалистически-значимой информацией о совершенном преступлении, а также имущества, на которое может быть наложен арест, для обеспечения возмещения причиненного преступлением вреда [2, с. 74]. В этом контексте направить запросы в Росфинмониторинг, налоговые органы.

Очевидно, что указанный перечень действий по проведению процессуальной проверке не является исчерпывающим, он может в зависимости от складывающейся следственной ситуации дополняться или корректироваться.

Действия лица, производящего расследование после возбуждения уголовного дела, должны в первую очередь быть направлены на обеспечение прав и законных интересов потерпевших и в то же время на установление и (или) доказывание причастности конкретных лиц к совершению расследуемого преступления в кратчайшие сроки $[4$, с. 40]. В этой связи необходимо на первоначальном этапе расследования фактов причинения имущественного ущерба путем обмана или злоупотребления доверием, совершенных в сфере производства, передачи и сбыта электроэнергии, организовать и провести следующие процессуальные, в том числе следственные действия:

- допустить в качестве законного представителя потерпевшего представителя юридического лица - ресурсоснабжающей организации;

- разъяснить ему право на возмещение имущественного вреда, причиненного преступлением;

- допросить представителя потерпевшего по обстоятельствам совершенного преступления; в протоколе допроса должны найти свое отражение следующие обстоятельства: когда, каким образом стало известно о факте совершения преступления - причинения материального вреда; где, когда, в какой пе- 
риод времени, каким образом он причинен и в каком размере; какие документы подтверждают данный факт; какими действиями был причинен материальный вред (несанкционированное подключение, использование специальных технических средств и пр.);

- осуществить выемку имеющихся у представителя потерпевшего документов, необходимых для полного и всестороннего установления всех обстоятельств события;

- в случае необходимости произвести обыск с целью изъятия недостающей гражданско-правовой и бухгалтерской документации;

- осмотреть изъятые документы;

- назначить необходимые почерковедчские и технико-криминалистические судебные экспертизы по имеющимся в распоряжении следствия документам;

- назначить необходимые экономические судебные экспертизы по имеющимся в распоряжении следствия документам;

- направить поручение органу дознания для установления лиц, причастных к совершению данного преступления, свидетелей данного преступления, а также местонахождения имущества, добытого преступным путем и др.

В случае установления лица (лиц), причастных к совершению данного преступления, и придания им процессуального статуса «подозреваемый» целесообразно установить их круг общения (родственники, близкие лица), у которых подозреваемые могут хранить документы и ценности, добытые преступным путем, затем произвести обыск по их месту жительства и работы, при этом особое внимание обращать на компьютерную технику и места хранения компьютерной информации, которая может способствовать как доказыванию вины подозреваемых, так и установлению имущества, на которое может быть наложен арест. Часть проводимых обысков или все указанные следственные действия, в зависимости от сложившейся следственной ситуации, целесообразно проводить одновременно, с целью нивелирования возможных действий заинтересованных лиц по уничтожению или сокрытию следов (в широком смысле слова) преступления [3, с. $159 ; 6$, с. 123].

При проведении обысков подлежат изъятию:
- бланки или черновики документов, документы, связанные с расследуемым фактом;

- печати и штампы, которые могли быть использованы при изготовлении бухгалтерских и гражданско-правовых документов;

- черновые и иные собственноручные записи подозреваемых (обвиняемых), в случае если в дальнейшем в ходе производства по уголовному делу планируется назначение почерковедческих судебных экспертиз;

- электронные носители информации;

- компьютерная техника и периферийные устройства, с помощью которых могли изготавливаться подложные бухгалтерские и гражданско-правовые документы.

Для установления путей «увода» денежных средств необходимо произвести выемку в соответствующих кредитных учреждениях документов, подтверждающих движение денежные средств по расчетному счету; их расходования и снятия.

В ходе последующего допроса подозреваемого (подозреваемых) необходимо установить:

- в каких организациях и на каких должностях работал ранее, уровень познаний в сфере электроэнергетики;

- какую должность и с какого времени занимал, каковы его должностные обязанности;

- каков установленный порядок совершения определенных действий в отношении имущества по распоряжению, управлению, доставке, пользованию или хранению и каково установленное нормативными правовыми актами документальное оформление указанных действий;

- как, когда и при каких обстоятельствах было совершено преступление;

- как, когда, каким способом, какие документы были изготовлены для придания вида законности совершаемым действиям.

При получении ответов на вышеуказанные основные вопросы следует самостоятельно определить перечень дополнительных вопросов исходя из полученной информации.

В случае если подозреваемый - должностное лицо конкретного юридического лица, до его допроса необходимо произвести выемку и изучить документы, подтверждающие его должностное положение: трудовой договор, приказ о назначении на должность, договор о 
полной индивидуальной или коллективной (бригадной) материальной ответственности.

\section{Выводы}

В заключение хотелось бы отметить, что знание организационных основ и тактических рекомендаций, а также специфики производства предварительного расследования по рассматриваемой категории уголовных дел, будет способствовать надлежащей реализации принципов уголовного судопроизводства.

\section{СПИСОК ЛИТЕРАТУРЫ}

1. Бирюков, С. Ю. Значение культуры речи в работе следователя / С. Ю. Бирюков, Д. Г. Скориков, А. А. Закатов // Вестник Волгоградской академии МВД России. - 2018. - № 3 (46). - С. 116-121.

2. Бирюков, С. Ю. Особенности возбуждения уголовных дел по фактам преступлений, сваязанных с незаконным выводом из Российской Федерации и невозвращением денежных средств в Российскую Федерацию / С. Ю. Бирюков, А. П. Резван // Вестник Волгоградской академии МВД России. 2018. - № 4 (47). - С. 74-80.

3. Соловьева, Н. А. Взаимосвязь процессуальной истины и разумных сроков ее установления / Н. А. Соловьева, В. М. Шинкарук // Вестник Волгоградского государственного университета. Серия 5, Юриспруденция. - 2014. - № 4. C. $159-164$.

4. Соловьева, Н. А. Уголовно-процессуальный риск: понятие и содержание / Н. А. Соловьева, В. М. Шинкарук // Вестник Волгоградского государственного университета. Серия 5, Юриспруденция. -2014 . - № 1. - С. 40-44.

5. Степанов, В. Предварительная проверка материалов, послуживших поводом к возбуждению уголовного дела / В. Степанов, В. Хомич // Законность. - 1995. - № 12. - С. 23-27.

6. Стешенко, Ю. С. О некоторых проблемах профилактики преступлений в сфере предпринимательства / Ю. С. Стешенко, С. Ю. Бирюков // Вестник Волгоградской академии МВД России. - 2013. Вып. 4(27). - С. 121-124.

7. Теоретические аспекты учебной дисциплины «Предварительное следствие в органах внутренних дел» / С. Ю. Бирюков, Ю. С. Стешенко, Е. В. Горкина, И. В. Макогон. - Волгоград : ВА МВД России, 2016. $-76 \mathrm{c}$.

\section{REFERENCES}

1. Biryukov S.Yu., Skorikov D.G., Zakatov A.A. Znacheniye kultury rechi $\mathrm{v}$ rabote sledovatelya [Meaning of Speech Culture in the Work of an Investigator]. Vestnik Volgogradskoy akademii MVD Rossii [Bulletin of the Volgograd Academy of the Ministry of Internal Affairs of Russia], 2018, no. 3 (46), pp. 116-121.

2. Biryukov S.Yu., Rezvan A.P. Osobennosti vozbuzhdeniya ugolovnykh del po faktam prestupleniy. svayazannykh s nezakonnym vyvodom iz Rossiyskoy Federatsii i nevozvrashcheniyem denezhnykh sredstv v Rossiyskuyu Federatsiyu [Features of Initiation of Criminal Cases on the Facts of Crimes Connected With Illegal Withdrawal From the Russian Federation and Non-Neturn of Funds to the Russian Federation]. Vestnik Volgogradskoy akademii MVD Rossii [Bulletin of the Volgograd Academy of the Ministry of Internal Affairs of Russia], 2018, no. 4 (47), pp. 74-80.

3. Solovyeva N.A., Shinkaruk V.M. Vzaimosvyaz protsessualnoy istiny i razumnykh srokov eye ustanovleniya [Relationship of Procedural Truth and Reasonable Terms of Its Establishment]. Vestnik Volgogradskogo gosudarstvennogo universiteta. Seriya 5, Yurisprudentsiya [Bulletin of Volgograd State University. Series 5, Jurisprudence], 2014, no. 4, pp. 159-164.

4. Solovyeva N.A., Shinkaruk V.M. Ugolovnoprotsessualnyy risk: ponyatiye i soderzhaniye [Criminal Procedural Risk: Concept and Content]. Vestnik Volgogradskogo gosudarstvennogo universiteta. Seriya 5, Yurisprudentsiya [Bulletin of Volgograd State University. Series 5, Jurisprudence], 2014, no. 1, pp. 40-44.

5. Stepanov V., Khomich V. Predvaritelnaya proverka materialov, posluzhivshikh povodom $\mathrm{k}$ vozbuzhdeniyu ugolovnogo dela [Preliminary Verification of Materials That Served as a Reason for Initiating a Criminal Case]. Zakonnost [Legality], 1995, no. 12 , pp. 23-27.

6. Steshenko Yu.S., Biryukov S.Yu. O nekotorykh problemakh profilaktiki prestupleniy v sfere predprinimatelstva [On Some Problems of Crime Prevention in the Sphere of Entrepreneurship]. Vestnik Volgogradskoy akademii MVD Rossii [Bulletin of the Volgograd Academy of the Ministry of Internal Affairs of Russia], 2013, no. 4 (27), pp. 121-124.

7. Biryukov S.Yu., Steshenko Yu.S., Gorkina E.V., Makogon I.V. Teoreticheskiye aspekty uchebnoy distsipliny «Predvaritelnoye sledstviye v organakh vnutrennikh del» [Theoretical Aspects of the Discipline "Preliminary Investigation in the Internal Affairs Bodies"]. Volgograd, VAMVD Rossii, 2016. 76 p. 


\section{Information About the Authors}

Svyatoslav Yu. Biryukov, Candidate of Sciences (Jurisprudence), Associate Professor, Head of the Department of Preliminary Investigation, Educational and Scientific Complex for Preliminary Investigation in the Internal Affairs Bodies, Volgograd Academy of the Ministry of Internal Affairs of the Russian Federation, Istoricheskaya St., 130, 400089 Volgograd, Russian Federation, Bir.slav@yandex.ru, https://orcid.org/0000-0002-7277-1926

Vladimir M. Shynkaruk, Candidate of Sciences (Jurisprudence), Associate Professor, Director, Institute of Law, Volgograd State University, Prosp. Universitetsky, 100, 400062 Volgograd, Russian Federation, shinkaruk@volsu.ru, shinkaruk_67@mail.ru, https://orcid.org/0000-0002-1047-4475

Mikhail A. Shmatov, Doctor of Sciences (Jurisprudence), Professor, Department of Preliminary Investigation, Educational and Scientific Complex for Preliminary Investigation in the InternalAffairs Bodies, Volgograd Academy of the Ministry of Internal Affairs of the Russian Federation, Istoricheskaya St., 130, 400089 Volgograd, Russian Federation, vitaliyshmatov@mail.ru, https://orcid.org/0000-0002-1736-704X

\section{Информация об авторах}

Святослав Юрьевич Бирюков, кандидат юридических наук, доцент, начальник кафедры предварительного расследования учебно-научного комплекса по предварительному следствию в органах внутренних дел, Волгоградская академия МВД России, ул. Историческая, 130, 400089 г. Волгоград, Российская Федерация, Bir.slav@yandex.ru, https://orcid.org/0000-0002-7277-1926

Владимир Маркович Шинкарук, кандидат юридических наук, доцент, директор института права, Волгоградский государственный университет, просп. Университетский, 100, 400062 г. Волгоград, Российская Федерация, shinkaruk_67@mail.ru, https://orcid.org/0000-0002-1047-4475

Михаил Андреевич Шматов, доктор юридических наук, профессор кафедры предварительного расследования учебно-научного комплекса по предварительному следствию в органах внутренних дел, Волгоградская академия МВД России, ул. Историческая, 130, 400089 г. Волгоград, Российская Федерация, vitaliyshmatov@mail.ru, https://orcid.org/0000-0002-1736-704X 